\title{
Is it time to introduce varicella vaccine to our children?
}

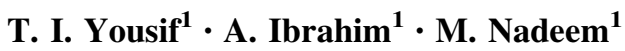

Received: 8 March 2016/Accepted: 3 May 2016/Published online: 9 May 2016

(C) Royal Academy of Medicine in Ireland 2016

\section{Dear Sir,}

Varicella is a common, highly infectious disease that occurs due to varicella-zoster virus infection [1]. Transmission is by inhalation of respiratory droplets, by direct contact with vesicular fluid, or by contact with fomites, with the incubation period from 14 to 16 days [2]. Varicella is due to primary infection, whereas zoster occurs with reactivation of latent virus [3]. It is a vaccine-preventable disease [1]; the live attenuated varicella vaccine has been recommended for routine use in immunization of children in some countries [4]. In Ireland, varicella (chickenpox) vaccine is not part of the routine childhood vaccination schedule; however, it is only offered to individuals who are particularly vulnerable to chickenpox [5], mainly immune-compromised or those on immunosuppressant. We reviewed cases admitted to Our Lady's Children Hospital, with complicated varicella zoster during the year of 2013. In total, 35 patients were admitted with complicated varicella infection, of which 3 patients had sepsis, 1 patient experienced encephalitis, and 10 patients had secondary bacterial infection, including cellulitis. In this group of patients, two out of five children with low albumin required albumin transfusion. Of the 35 patients, $1,3,3$, and 4 underwent brain MRI, CT, abdominal ultrasound, and chest X-ray, respectively. The average length of stay in the hospitals was 4-7 days, with five patients admitted for more than 8 days. The approximate cost of admission is 2000 euro per day, whereas a single dose of vaccine may cost 60-70 euro. Considering that the data we present are from one center involving only complicated cases as GPs and parents would manage many uncomplicated cases, it is obvious that varicella vaccination would be useful. We would recommend adding varicella vaccine to the national vaccination schedule.

\section{Compliance with ethical standards}

This is a retrospective study which involved only records review but no active involvement of participants. Consent was not required as this is a retrospective anonymized study.

Conflict of interest The author can declare no conflict of interest. We did not receive any grant from any source and no organization or institution has any influence on this paper.

\section{References}

1. Centers for Disease Control and Prevention (CDC) (2003) Decline in annual incidence of varicella-selected states, 1990-2001. MMWR Morb Mortal Wkly Rep 52(37):884-885

2. http://www.hse.ie/eng/health/immunisation/hcpinfo/guidelines/ chapter23.pdf. Accessed Aug 2015

3. Straus SE, Ostrove JM, Inchauspé G, Felser JM, Freifeld A, Croen KD, Sawyer MH (1988) NIH conference. Varicella-zoster virus infections. Biology, natural history, treatment, and prevention. Ann Intern Med 108(2):221-237

4. Wharton M (1996) The epidemiology of varicella-zoster virus infections. Infect Dis Clin N Am 10(3):571-581

5. http://www.hse.ie/eng/health/az/V/Varicella-chickenpox-vaccination
T. I. Yousif

drtaha2002@yahoo.com

1 Our Lady's Children's Hospital, Crumlin, Dublin 12, Ireland 